\title{
Team Convergence in Prevention and Reduction of Stunting Rate in Malang District, East Java, Indonesia
}

\author{
Wardani, Diadjeng S \\ Medicine Faculty of Brawijaya University, Malang, Indonesia
}

\section{ABSTRACT}

To reduce the incidence of stunting, the Central Government, through the Regional Government, made an acceleration effort, namely by forming a stunting convergence team at the regional level. This team consists of related agencies (in this study conducted at the village community empowerment service), village officials, and healthcadres. If the convergence of the stunting prevention team is good, then the program can run accordingly so that the stunting rate can decrease. The convergence team was formed starting in 2019, but the stunting rate in Malang Regency is still high. A quantitative study with a cross-sectional approach involving 378 stunting convergence teams in all villages in Malang District. Data analysis using multiple regression. The results showed that all indicators affecting the convergence of the stunting team in Malang Districtwere still low. From the results of regression analysis with a significance value of $p$-value $=0.001$, the value of the beta coefficient of the effect of team cohesiveness on team integration is 0.878 , the R-square value is 0.776 . This shows that $77.6 \%$ of team integration is influenced by team cohesiveness. The value of the Beta coefficient of the influence of leadership on team integration is 0.830 , R-square is 0.852 . This shows that $85.2 \%$ of team integration is influenced by leadership. To realize a good convergence of prevention teams and reduce stunting, team cohesiveness and leadership roles are needed. If team cohesiveness has been created properly and the leadership has played a maximum role, then team convergence will be good, the central government program can run accordingly, so that the incidence of stunting can be reduced.

\section{KEY WORDS: STUNTING, CONVERGENCE, TEAM,COHESIVENESS, LEADERSHIP.}

\section{INTRODUCTION}

Stunting is a condition in which toddlers have less length or height compared to age. This condition is measured by a length or height that is more than minus two standard deviations from the WHO median growth standard for children. Toddler stunting includes chronic nutritional problems caused by many factors such as socioeconomic conditions, maternal nutrition during pregnancy, illness in infants, and lack of nutritional intake in infants. Toddlers with stunting in the future will have difficulty achieving optimal physical and cognitive development.

Biosc Biotech Res Comm P-ISSN: 0974-6455 E-ISSN: 2321-4007

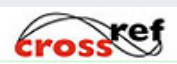

Identifiers and Pagination

Year: 2021 Vol: 14 No (5) Special Issue

Pages: $133-140$

This is an open access article under Creative

Commons License Attribn 4.0 Intl (CC-BY). DOI: $h$ ttp://dx.doi.org/10.21786/bbrc/14.5/26

Stunting prevalence data according to the World Health Organization (WHO), Indonesia is included in the third country with the highest prevalence in the Southeast Asia / South-East Asia Regional (SEAR). The average prevalence of stunting under five in Indonesia in 20052017 is 36.4\%. The prevalence of stunting under five in Indonesia tends to be static. The results of the Basic Health Research (Riskesdas) in 2007 showed the prevalence of stunting under five in Indonesia was 36.8\%. In 2010, there was a slight decrease to $35.6 \%$. However, the prevalence of short toddlers increased again in 2013 to $37.2 \%$. Based on the results of the 2015 PSG, the prevalence of stunting in Indonesia is 29\%. This figure has decreased in 2016 to $27.5 \%$. However, the prevalence of stunting has increased again to $29.6 \%$ in 2017.

Convergence Of Stunting Prevention Efforts: Prevention of stunting is carried out through integrated nutrition interventions, including specific nutrition interventions and sensitive nutrition. Global experience shows that implementing integrated interventions to target priority

Article Information

Received: $17^{\text {th }}$ Jan 2021

Accepted after revision: $27^{\text {th }}$ Mar 2021 
groups in priority locations is the key to the success of improving nutrition, child development and preventing stunting. Specific nutritional interventions target causes of stunting which include adequate food and nutritional intake, feeding, care and parenting, and treatment of infections / diseases. Efforts to accelerate stunting prevention will be more effective if specific nutrition interventions and sensitive nutrition interventions are carried out in a convergent manner.

Service delivery convergence requires integrated planning, budgeting, and monitoring of government programs / activities across sectors to ensure the availability of any specific nutrition intervention services to priority target families and sensitive nutrition interventions for all community groups, especially the poor.In other words, convergence is defined as an intervention approach that is carried out in a coordinated, integrated, and joint manner on target geographic areas and priority households to prevent stunting. Convergent intervention is carried out by combining or integrating various resources to achieve common goals.

Cohesiveness of the Stunting Prevention Convergence Team: The team's cohesiveness in previous studies was measured by three indicators namely personal attraction, sense of togetherness and group respect. Personal attraction makes it clear that it is part of the element that supports the achievement of cohesiveness in the team.To find out how the personal attraction in the stunting prevention convergence team is to measure the competence of team members, the relationships that exist within the team, the atmosphere created in the team, meetings held by the team, and the feeling of comfort that is felt by the team. The sense of interest among members in the stunting prevention convergence team will trigger the enthusiasm of the members to continue working together in providing services to pregnant women.

Leadership: Leadership is one of the competency dimensions that is crucial to the organization's performance or success. Leadership is an art, because everyone's approach to leading people can differ depending on the characteristics of the leader, the characteristics of the task and the characteristics of the person they lead. Based on the understanding of leadership from some of the expert opinions above, it can be concluded that leadership is closely related to a person's ability to be able to influence others to work according to the expected goals. This study measures the leadership of the Head of the Village Community Empowerment Service in this stunting prevention convergence team. Leadership is an interpersonal influence, which is exercised in certain circumstances, and is directed through the communication process towards the achievement of one or more specific goals. Leadership indicators are:

How To Communicate: Every leader must be able to provide clear information and for that he must have the ability to communicate well and smoothly. Because with good and smooth communication, of course this will make it easier for subordinates to grasp what a leader wants both in the short and long term. If a leader in transferring information is difficult for his subordinates or employees to understand and understand, it will cause problems. So that the ability to communicate for a leader really plays an important role in facilitating efforts to achieve company goals in relation to company operations

Motivator: A leader in addition to having the ability to communicate well and smoothly, of course, has the ability to provide encouragement or motivate financially or non-financially, that in terms of appreciation or recognition gives very high meaning to employees or subordinates. This will be able to create achievements and an atmosphere conducive to business success, where subordinates or employees will feel very cared for by their leaders who represent the company, with the hope that the achievements achieved so far will receive commensurate awards.

Leadership Style: Not every person or leader is able to lead, because with regard to a person's talents to have the ability to lead are different. This can be seen in the leadership style, whether it has an autocratic, participatory or free of control leadership style. Each has advantages and disadvantages. If someone with an autocratic leadership style, then the control of decision making will be entirely in the hands of the leader. If you use a participatory leadership style, the control of decision making includes employees, while the leadership style is free of control, the decision making is with the employees but is still under the full control of the leadership.

Decision-Making: A leader must be able to make decisions based on facts and regulations that apply in the company and the decisions taken can provide motivation for employees to work better and even be able to contribute to increased work productivity. The decisions that have been taken have been effective in instilling confidence in employees.

Positive Influence: A leader in running an organization or company, although with different leadership styles, of course, must provide a sense of security for employees who work. This fits perfectly with the leadership style through a humane approach, where employees are required to work wholeheartedly to produce good quality products, without any pressure from any party. A good leader will be able to have a positive influence, namely by providing good examples that can be imitated by his subordinates. This study concludes that these indicators are the two indicators used to measure the leadership head of the empowerment of village communities office (EFCO). The first indicator is the positive influence of the head EFCO on the stunting convergence team. The second indicator is leadership ability which consists of:

a. Communication skills of the head of the EFCO with the convergence team 
b. The ability of the head of the EFCO to motivate members of the convergence team

c. The ability of the head of the EFCO to create a family atmosphere within the convergence team

d. The way the head of the EFCO makes decisions within the convergence team

\section{METHODS}

This study used an analytic observational research design. This research was conducted through a survey method for data collection conducted by question and answer with questionnaires and interviews. This study will describe the situation in a population about the effect of team cohesiveness, organizational context and leadership on the integration of the stunting convergence team in Malang Regency. The research design used a cross-sectional design. The statistical method uses multiple regression analyst or multiple regression. Multiple regression is a regression or predictive model that involves more than one independent variable or predictor.

\section{RESULTS}

It shows that 179 teams (47.5\%) have less team cohesiveness, while only 93 teams (22.5\%) have good team cohesiveness. Next, it shows that 188 teams (50\%) rated the leadership as sufficient, while 112 teams (29.4\%) rated the leadership as lacking. The last shows that most of the stunting prevention teams have less team integration. This can be seen in the total column for the whole team, showing the largest number of $52.1 \%$ in the less category.

The Relationship Between Constructions (Structural Model): The discussion of the relationship between the extracts in the integration of the convergence team to prevent stunting, aims to explain the results of the structural model analysis, especially in the path diagram. Based on the results of the relationship analysis in the path diagram it is concluded that, team cohesiveness and leadership have a significant effect on the integration of the role of the convergence prevention stunting team.

\begin{tabular}{|c|c|c|c|c|}
\hline \multirow{2}{*}{ Context } & \multicolumn{3}{|c|}{ Category } & \multirow[t]{2}{*}{ Total } \\
\hline & Good & Enough & Less & \\
\hline Cohesiveness Team & $93(24.5 \%)$ & $106(28 \%)$ & $179(47.5 \%)$ & $378(100 \%)$ \\
\hline Leadership & $78(20.6 \%)$ & $188(50 \%)$ & 112 (29.4\%) & $378(100 \%)$ \\
\hline Integration team & $71(18.7 \%)$ & $110(29.2 \%)$ & $197(52.1 \%)$ & $378(100 \%)$ \\
\hline
\end{tabular}

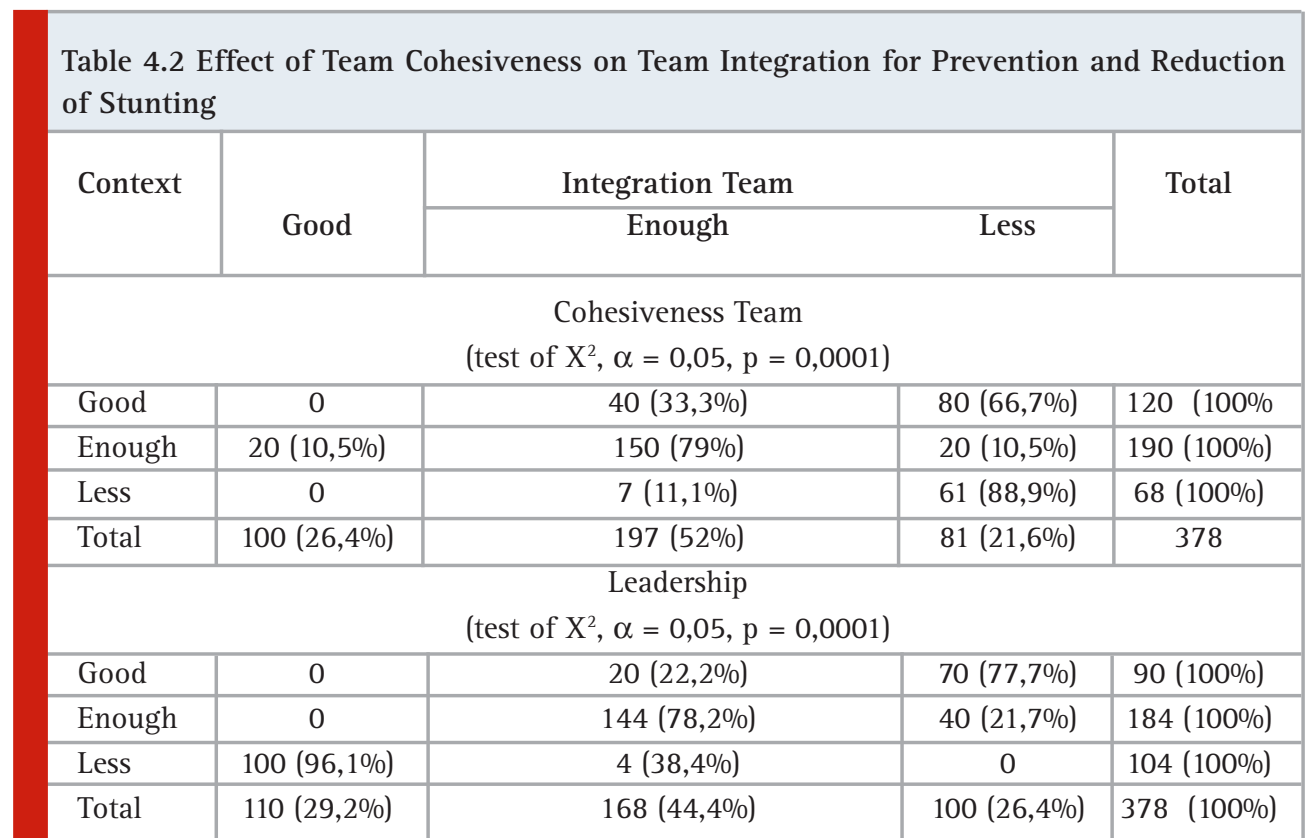

This shows that the effect of team cohesiveness on prevention team integration and the reduction of stunting has a significant effect. This can be seen from the results of the chi square analysis test, which obtained $\mathrm{p}$-value =
0.0001 at $\alpha=0.05$. This means that team cohesiveness has a probability to influence team integration. It can be concluded that the better the team cohesiveness, the more team integration tends to increase. 
From the test results show the influence of leadership on team integration has a significant influence. This can be seen from the results of the chi square analysis test, which obtained $\mathrm{p}$-value $=0.0001$ at $\alpha=0.05$, which means that leadership has a probability to influence team integration. It can be concluded that the better the leadership, followed by the increasing integration of the prevention team and the decrease in stunting.

From the test results above, it was found that all indicators of team cohesiveness had an effect on Integration team (p-value <0.05) with an R-square value of $80.5 \%$. The indicator of sense of togetherness has the greatest influence on IRHCP, namely the beta coefficient value of 0.698 and the value of $t=7.427$. From the test results above, it was found that all leadership indicators had an effect on the integration of the prevention team and the reduction of stunting ( $\mathrm{p}$-value $<0.05$ ), with an $\mathrm{R}$-square value of $88.8 \%$. Leadership ability indicators have the greatest influence on prevention team integration and a reduction in stunting, the beta coefficient is 0.810 and the $\mathrm{t}$ value $=14.602$.

Table 4.3 Multiple Regression Test Results Effect of Team Cohesivity Indicators on Team Integration for Prevention and Reduction of Stunting

\begin{tabular}{|c|c|c|c|c|}
\hline $\begin{array}{c}\text { Influence } \\
\text { Variable }\end{array}$ & Coefficient Beta & $\begin{array}{c}\mathrm{t} \\
\text { value }\end{array}$ & $p$-value & $R$-square \\
\hline Cohesiveness $\Rightarrow$ integration team & 0,878 & 13,126 & 0,001 & 0,776 \\
\hline Leadership $\Rightarrow$ integration team & 0,830 & 14,358 & 0,001 & 0,852 \\
\hline
\end{tabular}

Table 4.4 Multiple Regression Test Results Effect of Leadership Indicators on Team Integration for Prevention and Reduction of Stunting.

\begin{tabular}{|c|c|c|c|c|}
\hline $\begin{array}{c}\text { Indicator } \\
\text { Cohesiveness }\end{array}$ & $\begin{array}{c}\text { Coefficient } \\
\text { Beta }\end{array}$ & $\begin{array}{c}\mathrm{t} \\
\text { value }\end{array}$ & p-value & R-square \\
\hline Personal Attraction & 0,257 & 2,883 & 0,007 & \multirow{2}{*}{0,805} \\
\cline { 1 - 3 } Sense of togethemess & 0,678 & 7,424 & 0,002 & \\
\hline Group respect & 0,277 & 2,235 & 0,009 & \\
\hline
\end{tabular}

Table 4.5 Results of the Path Coefficient between Research Variables

\begin{tabular}{|c|c|c|c|c|}
\hline $\begin{array}{c}\text { Indicator } \\
\text { Leadership }\end{array}$ & $\begin{array}{c}\text { Coefficient } \\
\text { Beta }\end{array}$ & $\begin{array}{c}\mathrm{t} \\
\text { value }\end{array}$ & p-value & \multirow{2}{*}{ R-square } \\
\hline Leadership ability & 0,810 & 14,602 & 0,001 & \multirow{2}{*}{0,888} \\
\hline Positive influence & 0,585 & 10,552 & 0,001 & \\
\hline
\end{tabular}

From the results of regression analysis 1, the value of the Beta coefficient indicates that team cohesiveness has a strong influence on team integration, which is equal to 0.878 . The R-square value is 0.776 with a significance value of $\mathrm{p}$-value $=0.001$. This shows that $77.6 \%$ team integration is influenced by team cohesiveness, and the rest is influenced by other variables not examined in this study. From the results of regression analysis 2, the value of the Beta coefficient shows that leadership has a strong influence on team integration that is equal to
0.830. The R-square value is 0.852 with a significance value of $p$-value $=0.001$. This shows that $85.2 \%$ of team integration is influenced by leadership, and the rest is influenced by other variables not examined in this study.

\section{DISCUSSION}

Integration of Team: Integration in the team can be carried out well, marked by the existence of responsibility in the convergence team that must be carried out and completed together, the existence of an agreement on common goals in the team that is used as signposts for members in carrying out tasks, the process of delivering information, thoughts, and the ideas conveyed in the team, the existence of cooperation, mutual role play in accordance with the field of expertise in carrying out the work, and the overlapping of jobs that are felt by members of the convergence team.

Integration is defined as working collaboratively and continuously improving teamwork and attitudes from different professional backgrounds. The definition of integration describes two keywords, namely sharing and exchanging information. Assesses integration as the merging of individual and organizational goals into a single goal to be achieved. It is also an alignment of various processes for compatibility with one another[5]. Therefore, integration as working in a coherent way to overcome structural differences. For the stunting Convergence team, the indicators used to measure integration in this team are collective responsibility, common goals, good communication, collaborative roles and not overlapping jobs, it is considered on the basis of theoretical studies (literature review).

The integration of the Stunting Prevention Convergence team strengthens and represents the concept of team performance in the Team Effectiveness Model (Tannebaum et al., (1992) when explaining the phenomenon of how integration occurs in a team consisting of different educational backgrounds and expertise to be able to realize good team performance. Indicators of team integration in this study include collective responsibility, common goals, good communication, collaborative roles and not overlap jobs.

Based on the description, it is known that the integration of the convergence team to prevent stunting in terms of collective responsibility, common goals, good communication, collaborative roles and not overlap jobs is mostly in the sufficient category. An overview of the five indicators of Team Role Integration shows that good communication (good communication) has the largest percentage value compared to other indicators (65\%). It shows thatcommunication plays a big role in the success of integration in a team. The results showed that the good communication that occurred in the stunting convergence team was mostly in the sufficient category and a small part was lacking. This illustrates that there is a need for increased communication that occurs within the stunting convergence team. Participatory decision 
making, the interaction of the head of the EFCOwith the team in meetings, the relationship between the head of the EFCOand the team, the interaction of the team coordinator with team members, and clarity of the obligations of members in the team that are still lacking by most members of the stunting convergence team.

Collective responsibility in the team The convergence of stunting needs to be improved again to achieve good team integration. This includes how team members can jointly be responsible for doing work, how all team members are able to do work according to procedures, how team members want to admit mutual mistakes (without having to blame each other), and how all members manage time according to what set to get the job done on time.

Common goals relate to the agreement of common goals within the team that are used as signposts for members in carrying out their duties. By agreeing on shared goals in the team, member participation in the process of organizational activities will increase. Therefore, all will know well about what needs to be done in relation to the achievement of organizational goals. Seeing the phenomena that exist in the field, a possible strategy for the head of the EFCOis not to always make assumptions. This means that if you are not sure that all team members know what must be the top priority to be resolved, then the leader should ask the team members directly and always provide the information they need. If the leader is not sure that each member of the team knows how to do or complete a task, the leader must inform or show them how to do it.

Communication also needs to be done periodically for monitoring purposes (how far has the task been completed) and evaluating (whether there are errors that need to be corrected in completing the predetermined task). Role collaborative in the stunting convergence team is related to cooperation and mutually carrying out roles in accordance with their respective areas of expertise in carrying out tasks. Collaborative roles in this study include how the control of power between team members, whether team members contribute to each other, whether team members collaborate with each other according to their respective roles, and whether the mobilization of team members' abilities has been maximized.

The results showed that the collaborative role of the stunting convergence team was mostly sufficient and only a small proportion showed good collaborative role. This illustrates that there are still many team members who are too dominant, so that everything is done alone. This condition can also be the opposite, there are team members who are unemployed too much, so that there are irregularities in the team that will gradually make the team ineffective. Thus, each member of the team needs to be given the opportunity to become a 'leader' to demonstrate his expertise in the area of his competence and responsibility. By doing this, team members will feel responsible for the success of achieving common goals.

Not overlap jobs are related to the absence of overlapping jobs that are felt by members of the stunting convergence team. Not overlap jobs in the stunting convergence team include duplication of work done by team members, is there a similarity in workload among team members, whether team members handle work according to their part, and whether team members have ever completed work that is not their responsibility. The results showed that the division of labor in the Stunting Convergence team was largely sufficient, and a small proportion was balanced between the less and the already good. This illustrates that the division of tasks in the stunting Convergence team is not evenly distributed. Some team members still feel that there is an overlap of work between one another. The division of tasks is absolutely done in the organization so that there is no overlap in the implementation of work. So as not to cause a buildup of work at one point and vacancies at another.

From the five indicators described above, it can be concluded that the achievement of an effective team and a team whose members can be well integrated, it is strongly influenced by the existence of clear principles, goals and objectives, so that team members are consciously united by a shared mission and build a joint commitment. All team members understand and agree with the goals and objectives of the team. To achieve this, the role of the leader or the role of the team coordinator is needed in an effort to always provide guidance and direction to create an atmosphere in a good, solid and well-integrated work team so that better team performance can be achieved.

Team Cohesiveness Affects the Integration of the Stunting Prevention and Reduction Team: The results of the analysis show that team cohesiveness has a significant effect on the integration of the role of the convergence team to prevent stunting, the magnitude of the effect value is positive, meaning that the effect is unidirectional, indicating that if team cohesiveness is increased it will increase the integration of the role of the convergence team to prevent stunting. Team cohesiveness in this study is defined as the strength of the bond felt by team members that occur within the team, a sense of dependence between members, a sense of mutual cooperation, which will increase the capacity of members to achieve team goals. This team cohesiveness reinforces the concept of IRHCP from previous research, which explains that to be well integrated team members, there needs to be strong interest and ties in the team. This means that there must be strength for members to remain in the group, this is the power to hold someone in the group and prevent them from leaving the group. Cohesivity can be used as a motivation for someone to stay in the group.

The results of the analysis show that team cohesiveness has a significant effect on the Integration of the 
Convergence Prevention and Stunting Reduction Team, the magnitude of the value of the effect is positive, meaning that the value of the effect is unidirectional, indicating that if team cohesiveness is increased it will increase the integration of the convergence team for prevention and reduction of stunting. Team cohesiveness in this study is defined as the strength of the bond felt by team members that occur within the team, a sense of dependence between members, a sense of mutual cooperation, which will increase the capacity of members to achieve team goals. Based on the results of the analysis of this study, when the members of the Stunting Prevention and Reduction Convergence team perceive that in the team there is already interest among members of the team and comfort for the team in completing tasks, these two things can increase the unity of the members in the team. They realize that there are similarities between the members of the team. Individuals in cohesive teams are defined as strong feelings of being in integrated teams.

The literature review results explain that the more cohesive the group, the greater the level of member satisfaction. Members feel safe and protected, communication is more effective, free, open to each other, the easier conformity occurs, the easier it is to submit to group norms and the more intolerant of individual affairs. Good team cohesiveness can also be shown in the form of friendliness between members, they are usually happy to be together. Members also feel willing to accept responsibility for activities carried out to fulfill their obligations. All this shows the unity, closeness, and mutual attraction of group members. The results of this study explain that the indicators that can increase team cohesiveness have high scores in sequence, namely performance of task, sense of togetherness, and group respect.

This shows that to foster the integration of team members in carrying out tasks requires high cohesiveness in the team. Cohesiveness or cohesiveness will increase if in the team there is attraction between members, namely mutual trust and mutual support. This attraction serves to overcome obstacles in achieving goals. When the cohesiveness has been obtained, team members will feel more enthusiastic about carrying out the work in the team. Thus, in the team, considerable interdependence of members will be created, stability among group members, a feeling of responsibility from the results of the group's efforts, reduced absence, and resistance to interference so that maximum results can be achieved.

Leadership Affects Stunting Prevention And Reduction Team Integration: Leadership has a significant effect on team integration. The value of influence is positive, it means that the value of the influence is unidirectional, indicating that the better leadership will increase the integration of the convergence team. In this study, the ability of the head of the EFCO to lead and the ability of the head of the EFCO to have a positive influence were indicators in measuring leadership in the convergence team.
Leadership is one of the dimensions of competence that is crucial to the performance or success of a team. The essence of leadership is a way to influence others to be effective, but everyone can be different in doing what they receive. Leadership is an art, because everyone's approach to leading people can differ depending on the characteristics of the leader, the characteristics of the task and the characteristics of the person they lead. states that leadership is the process of inspiring all employees to work their best to achieve the expected results. This is important to motivate and coordinate members in the organization in order to achieve goals, the ability to create self-confidence and support among subordinates so that organizational goals can be achieved. It can be concluded that leadership is closely related to a person's ability to be able to influence others to work in accordance with the expected goals, so that in a team, leadership is very important to support the successful achievement of team goals. Campbell, J. (1990) also states that leadership is an effort to influence many people through communication to achieve goals, how to influence people with directions or orders, actions that cause others to act or respond and cause positive change. Humanistic theory looks at the function of leadership is to organize individuals or groups they lead in realizing their motivation so that they can jointly achieve their goals.

From the description above in accordance with the results of this study, namely the leadership indicator, the ability to lead is the most powerful indicator that can affect team performance. The ability to lead the head of theEFCO is the interaction between the head of the Dinas and the team members which is marked by the way the Dinas head has changed the behavior of the team member into someone who feels capable and highly motivated, and strives to achieve high quality work performance. The Head of Dinas can change team members so that the goals of his work group can be achieved together.

This is in line with Chapmann (2002,) which states that a good leadership pattern is when the leader is able to approach by doing business by changing awareness, arousing enthusiasm and inspiring subordinates or members of the organization to put extra effort in achieving organizational goals, without feeling pressured or depressed [6]. Burns (2002) states that leadership is a process of action affecting the activities of an organizational group in an effort to achieve predetermined goals. This leadership approach is carried out by making efforts to change the work environment, work motivation and work patterns and work values that are perceived by subordinates, so that they are better able to optimize performance to achieve organizational goals.

The second indicator is the ability of the head of officer to have a positive influence. This is also the leadership's strength to influence subordinates in certain ways so that subordinates will feel trusted, valued, loyal and respectful to their leaders so that in the end subordinates will be motivated to do more than expected, depressed so that with their own awareness they build a high commitment 
to achievement. The success in achieving goals, both as a whole and in various groups in a particular organization, really depends on the quality of the leader, in this case the head of the Public Health Centre. It can even be said that the quality of leadership contained in an organization plays a very dominant role in the success of the organization in the performance of its employees both individually or in teams. This can be interpreted that, if the leadership fails, the employee's performance also fails, on the contrary, if the leadership is successful, the employees will also produce good work as well.

\section{CONCLUSION / DISCUSSION}

The integration of the prevention team and the reduction of stunting, which was presented with indicators of collective responsibility, common goal, good communication, collaborative roles and not overlapping jobs in the team, showed sufficient results. Good communication is an indicator that has the strongest influence in the occurrence of good team integration. The local government, in this case, the Village Community Empowerment Service of Malang Regency, must think of the most appropriate way so that communication between team members can be maximized. If this goes well, the teamwork will increase.

Team cohesiveness which is used to strengthen the integration of the convergence team for stunting prevention is represented in the form of personal attraction (attraction between individuals in the team), sense of togetherness and group respect in this team showing sufficient categories. This must be further improved so that the main objective of team convergence in preventing and reducing stunting can be achieved. The leadership that has been done by the head of service is felt by most of the team members is quite good, but not a few who think that the leadership is felt still not good. Leadership is very important to move a team so that it can carry out its duties optimally. With good leadership, it will be able to create good team work results too.

\section{REFERENCES}

Armstrong, M. (2009) Armstrong's Handbook of Performance Management: an Evidence-Based Guide to Delivering High Performance. 4th ed. ISBN 978-07494-5392-3. CIPD. London.

Baiden, A. Price \& Dainty (2006) The extent of Team Integration within Construction Projects. International Journal of project Management, vol 24No 1. pp.1323.

Campbell, J. (1990) Modeling the Performance Prediction Problem in Industrial and Organizational Psychology ; in Handbook of Industrial and Organizational Psychology. Dunnette and L M Hugh. Cambridge, MA.

Cartwright, D \& Zander, A (1968) Group Dynamics: Research and Theory. New York. Harper and Row. pp. 76-78

Chapman, S. (2002) Electric Machinery and Power
System Fundamentals International edition. New York: Mc Graw Hill.

Dalgleish, T., Williams, J. M. G., Golden, A.-M. J., Perkins, N., Barrett, L. F., Barnard, P. J., Watkins, E. (2015). PENDEK (STUNTING ) DI INDONESIA, MASALAH DAN SOLUSINYA. Journal of Experimental Psychology: General (Vol. 136).

Driskell, J., Salas, E., Hogan, R. (1987) Personality and Group Performance. Inc. Henrick (Ed). Review of Personality and Social Psychology Journalvol 9. Newbury Park. pp 91-112

Fellowships, E. (2010). Funding Sources outside of the Psychology Department. Psychology, (1978), 16-23.

Head of National Planning Development Agency. (2015). Development Health and Nutrition Policy Planning, (2), 18.

Isabel, M., Pedro, M., Dias, C. (2014) What Team Members Perceive as Important to Achieve High Performance: an Exploratory Case Study. InternationalJournal of project Management vol 16. pp. 1010-1016.

Kim R, MejíaG, Ivá C, Aguayo VM, S. (2017). (2017). Relative Importance Child, Of 13 Correlates Of From, Stunting In South Asia: Insights From, Nationally Representative Data Afghanistan, Bangladesh, India Nepal, and Pakistan. Social Science \& Medicine.

Majzoub, K., flier, L., Helen. (2016) Behavioral Health Integration in Promary Care at Brigham and Women's Advanced Primary Care Associates. Health Care Journal vol 3(2015). pp. 169-174

Mary Beth, B. (2006) InterdisciplinaryHealth Care Teams : Organizational Context, Team Performance, Team Development, and Team Goals. Dissertation. The George Washington University School of Public Health and Health Services.

Ministry of Health Republic Indonesia (2018). Guidelines Intervention to Reduce Stunting. Ministry of Health Republic Indonesia

Persatuan Gizi Indonesia (PERSAGI), Ramayulis, R., Kresnawan, T., Iwaningsih, S., \&tRochani, nur'ainisusilo. (2018). STOP Stunting dengankonselinggizi. (M. Dr.atmarita, Ed.) (cetakan I). jakarta.

Rahman MS, Howlader T, M. M., \&t Rahman ML. (2016). Association of Low-Birth Weight with Malnutrition in Children under Five Years in Bangladesh: Do Mother's Education, Socio-Economic Status, and Birth Interval Matter?

Riskesdas. (2010). Riset Kesehatan Dasar; Badan Penelitian dan Pengembangan Kesehatan Kementerian Kesehatan RI Tahun2010. Laporan Nasional 2010, 1-384. https://doi.org/1 Desember 2013

Riskesdas. (2013). Penyakit yang ditularkanmelaluiudara. Jakarta: Badan Penelitian Dan Pengembangan Kesehatan Departemen Kesehatan Republik Indonesia, (Penyakit 
Menular), 103. https://doi.org/10.1007/s13398-0140173-7.2

Shanock, L. R., \& Eisenberger, R. (2006). , et al. . When Supervisor Feel Supported: Relationships With Subordinates Perceived Supervisor Support, Perceived Wardani, Diadjeng S. Fendy, Suhariadi. Damayanti, Nyoman A. (2017). Team Cohesiveness on Integration Role of Health Care Provider (IRHC) at Integrated Antenatal Care Team. Dama International Journal of Researchers (DIJR), Vol 2, Issue 9, September, 2017, Pages 101 - 111,

Wardani,Diadjeng S.Suhariadi,Fendy.Damayanti,
Nyoman A. (2017) dimension of integration on teamwork to improve good quality team performance. Scientia Research Library Journal of Applied Science And Research, 5 (1):58-67

Wardani. S. Diadjeng. Suhariadi, Fendy. Damayanti, Nyoman A. (2018)Organizational Context and Leadership in the Integration Role of Health Care Provider of Integrated Antenatal Care team in Public Health Centre. Indian Journal of Publich Health Research and Development Vol 9 No 5. pp. 285-287

Wilson, P., Goodman., Cronin. (2007) Group Learning. Academy of Management Review vol 32. pp 10411059. 